\title{
Evidencialidad de acervo común y folclore: patrones sociopragmáticos en el habla de Madrid
}

\author{
COMMON KNOWLEDGE AND FOLKLORE EVIDENTIALITY: SOCIOPRAGMATIC \\ PATTENS OF SPEECH IN MADRID
}

\section{Ana M. ${ }^{a}$ Cestero Mancera}

Universidad de Alcalá

Resumen

En este trabajo, se presentan los resultados de una investigación sociopragmática sobre evidencialidad de acervo común o folclore en el habla de la capital irradiadora de norma. Se parte de la idea de que la expresión de evidencialidad en español es estratégica y constituye, sobre todo, un recurso de atenuación; se considera, además, que, como ocurre en otros fenómenos pragmáticos, el uso y funcionamiento de la evidencialidad de sabiduría popular es variable sociolingüística y geolectalmente. Con objeto de conocer el rendimiento funcional de este tipo de evidencialidad, así como patrones de variación sociolectal y geolectal, se ha estudiado su aparición en un corpus de entrevistas orales semidirigidas de madrileños, el corpus PRESEEAMadrid, empleando una metodología común, establecida por Cestero y Kotwica (2021a, 2021b), que propone la realización de análisis cualitativos y cuantitativos detallados, de manera sistemática y homogénea. Los primeros hallazgos han permitido constatar que nos encontramos ante un recurso sociopragmático estratégico, que se utiliza escasamente en Madrid, y, cuando se hace, es mayoritariamente para atenuar y distanciarse, con ello, de lo dicho. Los hombres lo usan más que las mujeres, los adultos, más que los jóvenes y los mayores, y los sujetos de estudios medios, más que los de estudios superiores y básicos; ahora bien, son sociolectos concretos los que muestran proporciones más altas, lo que permite aventurar su futuro.

PALABRAS CLAVE: evidencialidad, folclore, acervo común, sociopragmática, PRESEEA
Abstract

This paper sets out the results of sociopragmatic research into common knowledge or folklore evidentiality in the speech of Madrid, Spain's norm-radiating capital. Its working assumptions are that the expression of evidentiality in Spanish is strategic and constitutes, above all, a resource for mitigating; and that, as with other pragmatic phenomena, the use and functioning of the popular knowledge evidentiality varies sociolinguistically and geolectally. In order to ascertain the functional performance of this type of evidence and patterns of sociolectal and geolectal variation, its occurrence has been studied in a corpus of semi-directed oral interviews with Madrilenians, the PRESEEA-Madrid corpus. A common methodology, as established by Cestero and Kotwica (2021a, 2021b), was employed, which aims at systematic and homogeneous qualitative and quantitative analyses. The preliminary findings confirm that it is a strategic sociopragmatic resource seldom used in Madrid. When it is used, it is mostly to mitigate and to distance oneself from what has been said. Men use it more than women, adults more than young and old people, and subjects with mid-level education more than those with higher or basic education. However, higher rates are found among specific sociolects, which enables their future to be predicted.

KEY WORDS: evidentiality, folklore, common knowledge, sociopragmatics, PRESEEA 


\section{INTRODUCCIÓN: LA EVIDENCIALIDAD DE ACERVO COMÚN}

Desde hace ya varios años, la evidencialidad, en lenguas sin categorías gramaticales específicas como la española, se ha convertido en un tema de estudio de gran interés, especialmente para semantistas y pragmatistas, por ser considerado un fenómeno de carácter semántico-funcional (Boye y Harder, 2009; Diewald y Smirnova, 2010; Albelda, 2015). De los tipos de evidencialidad reconocidos, quizás el que menos atención haya recibido hasta ahora y, por ello, el que menos profunda y sistemáticamente haya sido investigado es la evidencialidad de folclore, entendida como evidencialidad indirecta transmitida (Willet, 1988), que puede definirse como aquella en la que la información se origina en acervo común o saber popular compartido (Willet, 1988; Lazard, 2001; Bermúdez, 2005).

Recientemente, Kittilä (2020) ha precisado más los rasgos distintivos de folclore, considerándolo como patrimonio cultural transmitido de generación a generación, del que el hablante no posee evidencia personal y cuya fuente de información permanece desconocida, y que tiene valor de verdad por tratarse de bien cultural. Además, lo relaciona con otro tipo de evidencialidad (general knowledge) y, de forma especial, con su variante más prototípica: generally known truths (Kittilä, 2019: 1283). Es en esta confluencia en la que se enmarca el estudio que aquí presentamos: evidencialidad a través de acervo común, pues atendemos a las dos clases como una única, en la que el contenido es saber compartido, pero expresado a través de construcciones diferentes, bien unidades fraseológicas, esto es, paremias, bien estructuras no fijadas que contienen creencias estereotipadas generalizadas. Dado que el objeto de estudio va más allá de lo habitualmente considerado folclore, utilizamos etiquetas variadas para referirnos al contenido que nos ocupa, empezando por acervo común y folclore, pero alternándolas con saber compartido y sabiduría popular.

Tal y como afirma Briz (2016), la evidencialidad en español es siempre funcional, pues, en una lengua no evidencial como la nuestra, la expresión de la procedencia de información, en nuestro caso originada en acervo común, se emplea con ciertos valores pragmáticos relacionados con imágenes o (des)cortesía (Albelda, 2016; Estellés y Albelda, 2017), de entre los que destacan, o quizás sean los únicos, la atenuación o la intensificación y el refuerzo, como propósitos fundamentales o contextuales (Briz, 2016: 122; Kotwica, 2019, 2020a, 2020b). Como recurso atenuador, presentar la información como procedente de una fuente externa, y más si dicha información es una verdad generalizada o producto de sabiduría popular compartida, permite al hablante mostrarse como no responsable de ella y objetivarla (Albelda y otros, 2014; Cestero, 2020; Cestero y Albelda, 2020; Albelda y Cestero, 2020); precisamente la objetivación y validación que confiere la evidencialidad puede servir, a la vez o en otras ocasiones, para apoyar un razonamiento que, en el caso de contenido de acervo común, constituye un recurso de refuerzo o intensificación (Briz, 2016; Albelda, 2020; Estellés, 2020). Por tanto, se hace necesario investigar el fenómeno desde la Pragmática, el enfoque más desarrollado en la actualidad, que hemos querido completar en el trabajo del que aquí damos cuenta aportando un marco teóricometodológico más amplio y multidisciplinar, que permite contemplar los factores de diversa 
índole (lingüísticos, enunciativos, pragmáticos, sociales y culturales) que inciden en el empleo de evidencialidad a través de acervo común en interacción comunicativa natural.

En las páginas que siguen, presentamos el estudio que hemos llevado a cabo sobre evidencialidad de folclore o acervo común en el habla de Madrid', de corte sociopragmático, que nos ha llevado a conocer, por un lado, el rendimiento funcional de este recurso de atenuación o refuerzo en interacción oral en registro semiformal y, por otro, patrones de uso, lingüísticos y sociolingüísticos, en la capital española. Para su realización, se han establecido variables y variantes específicas, que han permitido perfilar una metodología de investigación probada y validada en el seno del macroproyecto internacional PRESEEA (Proyecto para el estudio sociolingüístico del español de España y América), del que se nutre en su marco teórico-metodológico (Cestero y Kotwica, en prensaa y en prensab).

\section{EL ESTUDIO DE EVIDENCIALIDAD A TRAVÉS DE ACERVO COMÚN EN EL CORPUS PRESEEA: METODOLOGÍA DE LA INVESTIGACIÓN}

Este trabajo y el de Dorota Kotwica (2021) de este mismo volumen presentan la primera investigación realizada sobre evidencialidad de folclore desde una perspectiva sociopragmática, y se ha llevado a cabo en el marco del macroproyecto internacional conocido como PRESEEA (Proyecto para el estudio sociolingüístico del español de España y América) $)^{2}$.

El objetivo general es conocer el uso y funcionamiento de evidencialidad a través de folclore o acervo común en el español hablado del siglo XXI. Para ello, consideramos que lo más adecuado era iniciar una investigación coordinada, que, por tratarse de un acercamiento de corte sociolingüístico en el que se aplica la misma metodología y se trabaja con corpus de similares características de distintas comunidades de habla hispana, permitiera dar cuenta del rendimiento funcional del recurso estratégico, como resultado del estudio sistemático de todas las dimensiones incidentes, y comparar resultados para establecer patrones sociopragmáticos y geolectales.

La metodología de la investigación coordinada se recoge en la Guía PRESEEA de estudio de la evidencialidad de folclore o acervo común (Cestero y Kotwica 2021a) y en Cestero y Kotwica (2021b). Trabajamos desde una perspectiva interdisciplinar que combina el análisis de la conversación, la pragmática y la sociolingüística, analizando, cualitativa y cuantitativamente, la aparición del tipo de evidencialidad que nos ocupa en los corpus PRESEEA, en nuestro caso, en 72 entrevistas del corpus PRESEEA-Madrid. Las grabaciones han sido seleccionadas con completo control de variables sociales; así,

\footnotetext{
${ }^{1}$ Este artículo se inscribe dentro de las actividades científicas de los siguientes proyectos de investigación: AGENDA 2050. El español del centro-norte de España: procesos de variación y cambio espaciales y sociales (VARES-AGENDA50; PID2019104982GB-C51), del Ministerio de Ciencia, Innovación y Universidades, y La población migrante de la comunidad de Madrid: factores lingüísticos, comunicativos, culturales y sociales del proceso de integración y recursos lingüísticos de intervención (IN.MIGRA3-CM; ref. H2019/HUM-5772), financiado por la Comunidad de Madrid y el Fondo Social Europeo.

2 Para conocer en mayor detalle el Proyecto para el estudio sociolingüístico del español de España y América (PRESEEA), puede consultarse Moreno Fernández (1996, 2006), Cestero (2012), Moreno y Cestero (2020). Véase, también, el portal del proyecto: https://preseea.linguas.net/.
} 
hemos elegido las muestras de 4 hombres y 4 mujeres, de cada uno de los grupos etarios establecidos en PRESEEA (de entre 20 y 34 años, de entre 35 y 54 años y de 55 años o más) y de cada nivel de instrucción contemplado en el macroproyecto (con estudios primarios, con estudios medios, con estudios superiores). Además, dado que, en Madrid, se han recogido materiales de dos zonas habitualmente asociadas a determinadas clases sociales, hemos elegido la mitad de los sujetos del distrito de Salamanca (clases medias y medias altas) y la otra mitad del distrito de Vallecas (clases medias y medias bajas).

En los corpus PRESEEA, la duración media de las grabaciones es de 45 minutos; no obstante, dado que se trata de encuestas semidirigidas a través de módulos temáticos para conseguir homogeneidad en el tratamiento de temas (el tiempo, lugar donde se vive, familia y amistad, costumbres, peligro de muerte, anécdotas importantes en la vida, deseo de mejora económica), algunas duran algo menos de 45 minutos y otras bastante más. Con objeto de poder comparar lo que acontece en toda la muestra y obtener, así, más casos de uso de evidencialidad de acervo común en interacción comunicativa oral, hemos analizado las encuestas completas (63 horas, 34 minutos y 08 segundos de habla); los resultados de estos análisis nos permiten dar cuenta de la forma de uso habitual del recurso estratégico en el habla de Madrid, sobre todo, de las marcas de evidencialidad que se emplean y del tipo de enunciado que contiene saber compartido más habitual. Ahora bien, para comparar de forma más precisa y sencilla, cruzar datos y evitar la incidencia en los resultados de diferentes tamaños de muestras, la mayoría de los análisis cuantitativos los hacemos sobre 30 minutos de cada entrevista, siempre que es posible, del minuto 5 al 35 (36 horas de grabación de habla), para favorecer, además, la realización del estudio sobre fragmentos en los que se desarrollan los mismos temas.

El corpus está conformado con entrevistas semidirigidas, de manera que nos encontramos ante situaciones de no mucha solidaridad o inmediatez comunicativa; sin embargo, se considera que los sujetos van modificando el registro de lengua a medida que avanza la interacción, por lo que, si bien se empieza con un habla que tiende a la formalidad o semiformalidad, lo más común es que vaya bajando en grado hasta llegar, en algunos casos, a muestras muy próximas a interacciones con rasgos propios de registros informales. Con objeto de comprobar si la posible variación de registro incide en el empleo del tipo de evidencialidad que nos ocupa, trabajamos con tres intervalos de tiempo controlados: los primeros 10 minutos se consideran los más cercanos a la formalidad, los segundos 10 minutos, de registro medio, y los terceros 10 minutos, los de menor formalidad.

En la investigación, partimos del acto de habla como unidad básica y llevamos a cabo dos tipos de análisis sobre el corpus en fases sucesivas: en primer lugar, un análisis cualitativo, que permite identificar y describir el funcionamiento del fenómeno y las características formales que presenta habitualmente; en segundo lugar, un análisis cuantitativo, que proporciona información sobre la frecuencia de aparición de variables y variantes, así como las relaciones existentes entre ellas y la incidencia que en las mismas tienen la edad, el sexo y el nivel de instrucción de los informantes. Las variables y variantes con las que trabajamos fueron establecidas a partir de un estudio piloto efectuado sobre 18 entrevistas del corpus de Madrid y 18 del corpus de Valencia; los análisis posteriores nos permitieron 
perfilarlas y considerarlas relevantes en el recurso estratégico, y ofrecerlas en conjuntos de variables y variantes lingüísticas, pragmático-discursivas y sociales que intervienen y configuran la evidencialidad de acervo común en la interacción oral. La nómina queda organizada en grupos, tal y como se especifica a continuación:

1) Función de la evidencialidad a través de folclore o acervo común

La función de la evidencialidad se considera la variable dependiente o de análisis, pues nuestro estudio es de corte sociopragmático. Teniendo en cuenta las posibilidades funcionales del fenómeno, se distingue entre las dos funciones constatadas: atenuar o reforzar una argumentación.

\section{Factores lingüísticos}

2) Marca de evidencialidad a través de folclore o acervo común

Se identifica la expresión lingüística señalizadora de alusión a conocimiento obtenido de otros. Aunque también se anota la forma concreta utilizada por los hablantes, se trabaja con lemas que permiten efectuar análisis cuantitativos y nos muestran las bases de las marcas de uso frecuente. La nómina no está cerrada; aquí trabajamos con los hallados en nuestro corpus.

3) Posición discursiva del elemento introductor en el miembro discursivo al que afecta

Con relación a la producción de la marca en la estructura proposicional, cuando se usa alguna, se tienen en cuenta las siguientes ubicaciones, que se consideran variantes: inicial integrado en la estructura discursiva, intermedio integrado y final integrado; inicial no integrado en la estructura discursiva, esto es, parentético, intermedio no integrado y final no integrado.

4) Número de marcas de evidencialidad a través de folclore

Se constata y analiza el número de marcas empleadas por los hablantes en cada acto de habla, pues supone una forma de gradación del recurso estratégico.

5) Tipo de enunciado de folclore

Trabajamos con dos tipos de enunciados de acervo común: enunciados fraseológicos, esto es, fijados en la lengua (refranes, dichos, sentencias, etc.) y creencias generalizadas estereotipadas no fijadas lingüísticamente.

6) Co-construcción de la evidencialidad

Se tiene en cuenta, además, si hay una co-construcción de la evidencialidad entre el hablante y el entrevistador o no. En caso de que la haya, se diferencia entre dos variantes: el hablante introduce el enunciado de folclore, pero sin marca, y la marca la aporta el entrevistador; es el entrevistador quien introduce el enunciado de folclore sin marca, que es aportada por el hablante.

\section{Factores pragmáticos y discursivos}

7) Tipología textual en la que aparece evidencialidad por folclore 
Se constata, ya como factor pragmático-discursivo, la modalidad textual en la que se produce el acto de habla con evidencialidad, distinguiendo, como en otros estudios PRESEEA, entre exposición, narración, descripción, argumentación e intervención ritualizada.

8) Fuente de información

Como forma de organización del dominio de la evidencialidad, se comprueba y anotan las fuentes de información, si aparecen. En este caso, no hay una lista de variantes establecidas, pues depende de cada corpus e informante.

9) Acceso a la información

Se atiende, también, a si el acceso a la información es ambiguo o el acervo común es de uso generalizado o restringido a área local.

10) Contenido de lo dicho en relación con las imágenes de las personas

Para establecer la base funcional del empleo de evidencialidad de folclore, se analiza cada caso según la carga semántico-pragmática del mensaje, teniendo en cuenta las imágenes implicadas en el acto de habla y, con ello, si no se da autoprotección porque no hay imágenes implicadas o si la imagen implicada es la del hablante, la del interlocutor o la de otras personas no presentes en la actividad interaccional. En estos últimos casos, se considera que la evidencialidad protege la imagen del hablante, la del interlocutor o la de otros.

11) Fuerza ilocutiva del acto de habla

En estrecha relación con el contenido de lo dicho, hemos estudiado si el tipo de acto de habla con discurso atenuado, según su fuerza ilocutiva, establecido a partir de la clasificación básica de los actos de habla en directivos (en beneficio del hablante o en beneficio del interlocutor), asertivos (expresión de opiniones o expresión o descripción del estado factual de la realidad), compromisivos y expresivos, incide en el funcionamiento sociopragmático del recurso estratégico.

\section{Factores situacionales}

Hemos tenido en cuenta otras variables pragmático-discursivas básicas, consideradas muchas de ellas en los estudios coordinados PRESEEA, que permiten controlar factores condicionantes de la variabilidad en circunstancias determinadas:

12) Temática

Se consideran tres variantes: tema cotidiano, tema especializado y fórmulas rituales.

13) Fin de la interacción

Se distingue entre interpersonal y transaccional, pues, aunque se trata de entrevistas semidirigidas, se intenta obtener interacción cercana a la conversacional.

14) Registro

Se establecen tres intervalos que pueden considerarse puntos del continuum de registros, los primeros 10 minutos son los más formales, seguidos de los segundos 10 
minutos, que se consideran más de registro neutro, y los terceros 10 minutos, en los que se anota una tendencia hacia la informalidad.

\section{Factores sociales}

Con respecto a los factores sociales, y siguiendo los presupuestos metodológicos del PRESEEA, trabajamos con las siguientes variables y variantes:

15) Sexo

Distinguimos entre informantes hombres y mujeres.

16) Edad

Los informantes pertenecen a uno de tres grupos etarios preestablecidos: jóvenes -de 20 a 34 años-, adultos -de 35 a 54 años- y mayores -55 años o más-.

17) Nivel de instrucción

Se tienen en cuenta tres posibilidades: sujetos sin estudios o con estudios primarios, con estudios secundarios -medios- y con estudios superiores.

Por último, no podemos olvidar que un presupuesto básico del proyecto PRESEEA es comparar los resultados obtenidos en los diferentes estudios realizados; por ello, se contempla la variación diatópica y cultural como fundamental. A este respecto, hemos trabajado en coordinación con Dorota Kotwica (2021, en este volumen), que ha analizado PRESEEA-Valencia, lo que nos ha permitido llevar a cabo un trabajo contrastivo que tiene por objeto establecer patrones sociopragmáticos de la atenuación en dos comunidades, Madrid y Valencia, como inicio de la investigación coordinada que pretende dar cuenta, también, de patrones geolectales y culturales (Cestero y Kotwica, 2021b). Pasamos ya a detallar los resultados del estudio al que se dedica este artículo, esto es, del uso de evidencialidad de folclore o acervo común en el habla de la gran urbe española.

\section{EVIDENCIALIDAD A TRAVÉS DE ACERVO COMÚN EN EL HABLA DE MADRID}

En el corpus de encuestas semidirigidas de madrileños, se han identificado un total de 155 casos de evidencialidad empleando una expresión de folclore o con mensaje de saber compartido, lo que indica que no se trata de un recurso habitual en registro semiformal, al menos en la interacción de los sujetos de la urbe irradiadora de norma. Los 155 casos se han documentado en un total de 63 horas, 38 minutos y 08 segundos, en los que se han emitido 714847 palabras y 27053 turnos de informante, de los cuales 220 tienen el tipo de evidencialidad que nos ocupa. Además, como se ha explicado en el apartado previo, podemos controlar lo que acontece en un mismo periodo de tiempo, 30 minutos, en los que se tratan los mismos temas o muy similares; ahora, el número de casos documentados se reduce un tercio, pues se han encontrado 100 ejemplos, en 36 horas de grabación de habla de madrileños, en las que se registran 406778 palabras y 15052 turnos de informante, de los que 147 tienen evidencialidad de folclore o acervo común, y nos permite conocer patrones sociopragmáticos actuales y aventurar cierta proyección futura. 
Aunque los casos documentados son escasos, muestran, a nuestro entender, tendencias interesantes y dan cuenta de estrategias de uso y recursos frecuentes, a la vez que aportan diferencias sociolectales en el empleo de evidencialidad a través de folclore o sabiduría popular compartida. Ofrecemos, a continuación, los resultados más destacados obtenidos en la investigación llevada a cabo.

\subsection{Funciones de la evidencialidad de folclore o acervo común}

La primera dimensión de la evidencialidad con la que hemos trabajado, tomada como variable dependiente, es la función para la que se emplea evidencialidad a través de folclore o acervo común en las interacciones comunicativas objeto de estudio. Como se especificó al exponer la metodología de la investigación, hemos considerado tres posibilidades en atención al tipo de evidencialidad que nos ocupa: su empleo para atenuar mediante un procedimiento de desfocalización, esto es, recurriendo al saber común y popular como fuente de información objetiva y general, de manera que quedan protegidas las imágenes implicadas, bien la del propio hablante o bien la del interlocutor u otras personas; su uso como refuerzo argumentativo, que se consigue presentándola como más válida que la propia por provenir de sabiduría popular o compartida, lo que la objetiva y la muestra como general o ampliamente conocida; por último, hemos documentado, también, algunos casos en los que no parece posible discernir si el hablante hace uso de la evidencialidad para atenuar o para reforzar, por lo que los hemos tomado como ambiguos.

Los resultados obtenidos con relación a la función de la evidencialidad a través de folclore son contundentes: los madrileños la emplean, fundamentalmente, como recurso de atenuación (así es en 113 caso, el 72,9\% del total) y, en mucha menor proporción, como refuerzo de posturas y argumentaciones (así ocurre en 38 casos, el 24,5\%). Es puramente circunstancial que no quede clara la función, pues solo ocurre en 4 ocasiones (el 2,4\%) de la muestra3.

\footnotetext{
${ }^{3}$ El tipo textual en el que aparecen los casos de evidencialidad en el corpus es prácticamente siempre argumentativo (82\%) o expositivo (13\%), lo que resulta normal dada la clase de evidencialidad con la que trabajamos, por lo que, en el corpus analizado, no resulta relevante la variable de tipología textual.
} 


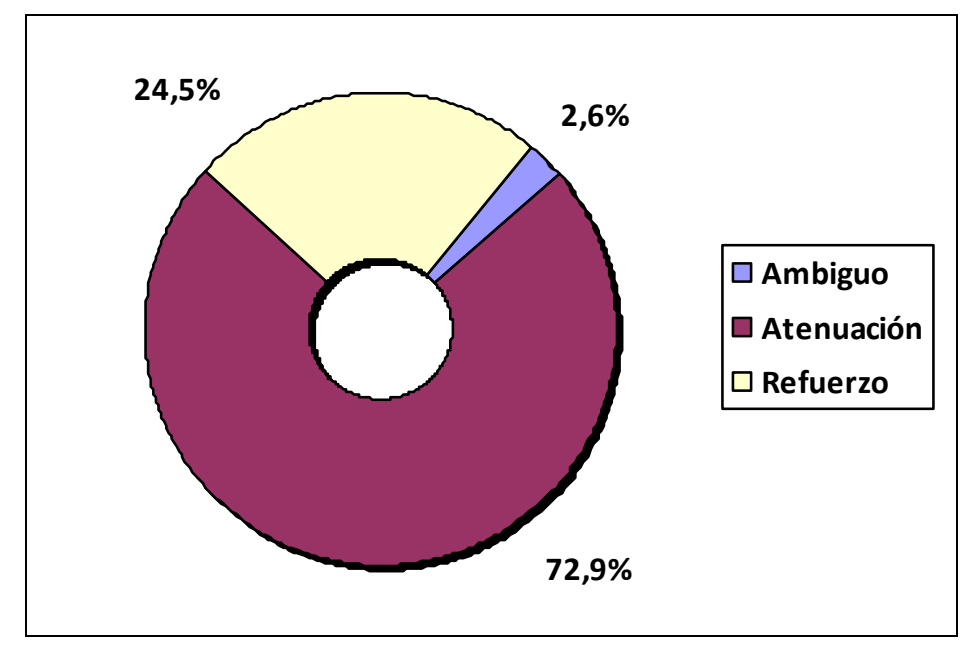

Gráfico 1. Función de la evidencialidad de saber común en el habla de Madrid.

Sig. asintótica de la prueba Ji²: ,000 - Media: 1,22; Desviación típica: ,474; Varianza: ,224

Estos datos nos llevan a considerar la evidencialidad de saber común básicamente como una estrategia atenuadora de distanciamiento para aportar objetividad y generalización, lo que, de alguna manera, siempre refuerza. Se trata del recurso de atenuación más indirecto de los de uso frecuente en español (Cestero, 2020; Cestero y Albelda, 2020), que opera mediante la impersonalización o la desfocalización, poniendo el origen de la información que se aporta, ya sea con actos de habla asertivos de opinión o asertivos de información (81\% y $19 \%$ de los casos, respectivamente), en la sabiduría popular o el conocimiento compartido, con lo que se evita, a la vez, comprometer la imagen propia o la de otros. De hecho, en el $28 \%$ de los casos de empleo de evidencialidad de saber compartido no están comprometidas imágenes (así ocurre en los 28 casos en los que la función identificada es reforzar), mientras que en los 72 restantes se intenta atenuar precisamente para proteger las imágenes comprometidas (en el 36\% de los casos del corpus de Madrid la del propio hablante, en el 3\%, la del interlocutor y en el 33\%, la de otros sujetos). Más adelante daremos cuenta de las tendencias sociolectales que se vislumbran en el corpus de habla analizado en relación con las funciones del tipo de evidencialidad que nos ocupa.

\subsection{Evidenciales de uso frecuente en el habla de Madrid}

Como se comentó en el apartado de metodología, las primeras variables independientes analizadas son las de tipo formal y responden al interés por conocer qué evidenciales se emplean en el habla de Madrid y cuál es su posición habitual en el acto comunicativo con evidencialidad de sabiduría popular.

Los hallazgos son los esperables; ahora bien, los análisis estadísticos nos permiten confirmarlos y considerarlos significativos. En el corpus completo analizado, se han documentado un total de 166 marcas de evidencialidad; en la mayoría de los casos, los hablantes emplean solo una en el mismo acto comunicativo; en 19 ocasiones, se usan 2 marcas y en 2, tres, y son 12 las ocasiones en las que no hacen uso de marcas al evidenciar 
con refranes, dichos u otras unidades fijadas en la lengua. Lógicamente, es más frecuente que se empleen marcas evidenciales que marcas de modalidad epistémica objetiva, que sirven aquí como evidenciales también (así es en el 67,5\% de los casos -112-, frente al $32,5 \%-54-)$.

El evidencial de uso más frecuente (66,9\% de las marcas evidenciales y 45,2\% de todas las marcas) es el prototípico decir, que se presenta en formas de conjugación y estructuras diversas, de entre las que destacan dicen que, como dicen/dice y dice + cita. Le siguen en frecuencia de empleo, aunque muy de lejos, las marcas con saber (7 casos, 6,3\% saben/sabemos que, ya sabes), pensar (6 casos, 5,4\% -piensan/pensaban que), oír (4 casos, 3,6\% -se oye, ol) y parecer (4 casos, 3,6\% -al parecer, parece ser que). El resto de marcas es de empleo ocasional, tanto las de base verbal (con hablar, comentar, oír hablar, escuchar, considerar, contar, leer) como las de base nominal o pronominal (una frase + cita, costumbre, dicho, refrán, eso + cita).

Por otro lado, los marcadores de modalidad epistémica empleados como evidenciales de uso más frecuente en Madrid son claro (con 18 casos, el 33,3\% de las marcas modales y el $10,8 \%$ de todas las marcas -claro, está claro) y verdad (con 17 casos, el 31,5\% de las marcas modales y el 10,2\% de todas las marcas -la verdad, la verdad es, es verdad que, verdaderamente). Siguen en frecuencia de uso marcas formadas con realidad (8 casos realmente, la realidad es, en realidad), evidente (4 casos -evidentemente, es evidente) y cierto (4 casos -es cierto que). El resto de unidades es de utilización ocasional (indiscutiblemente, seguro, indudablemente).
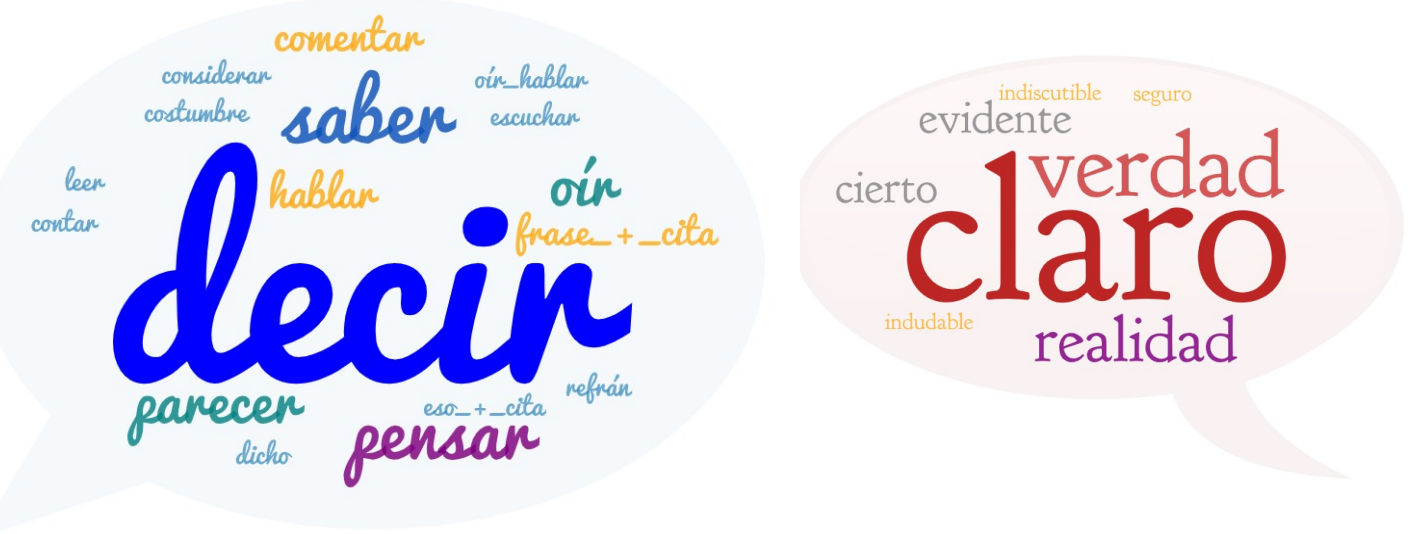

\section{Gráfico 2. Evidenciales y modalizadores empleados en el habla de Madrid}

Con relación a la posición en la que se emite la expresión lingüística señalizadora de alusión a conocimiento compartido respecto al fragmento al que afecta, hemos de resaltar que lo más habitual es que sea inicial integrada ( 75 casos de los 166 documentados con marca, el 45,2\%) o intermedia integrada (30 casos, el 18,1\%), aunque es relativamente frecuente, también, que se produzca en posición inicial parentética (22 casos, el 13,3\%) e intermedia parentética (19 casos, 11,4\%); en menor medida aparece en posición final parentética (14 casos, el 8,4\%) y final integrada (6 casos, el 3,6\%). La correlación entre tipo de marca 
empleada y posición discursiva es muy clara también; así, las construcciones con decir suelen preceder a la expresión del saber común o colocarse en posición intermedia de la misma, integrándose casi siempre en la estructura oracional (en 43 casos inicia y en 18 se intercala -de los 75 ejemplos de marcas con decir). Por el contrario, la marca modal que se ha empleado más asiduamente en el corpus, claro, aparece habitualmente en posición parentética, ya sea antes (6 casos), durante (7 casos) o al final (3 casos) de la expresión del saber compartido. Las construcciones con verdad, la tercera marca más usada por los madrileños, presentan un mayor equilibrio entre integración (inicial -9 casos-) y no integración (final -4 casos- e intermedio -2 casos-) en la estructura gramatical del enunciado.

Por otro lado, resulta interesante comprobar que, al menos en el tipo de interacción comunicativa analizada (transaccional con pretensión de acercamiento a conversacional), no hay prácticamente construcción conjunta de evidencialidad a través de folclore o saber común. Solo ha ocurrido la co-construcción en 10 ocasiones en todo el corpus, 1 con refrán y las demás con expresión de creencia estereotipada, 6 en las que el informante aporta la marca de evidencialidad y 3 , en las que introduce el enunciado.

Por último, no podemos pasar por alto el hecho de que es excepcional en el habla de Madrid que la sabiduría popular o común se enuncie utilizando una unidad fraseológica (refranes, dichos, sentencias, etc.), ya que se ha documentado como habitual que el enunciado de la evidencialidad, creencia generalizada estereotipada, no sea una construcción fijada en forma y significado en la lengua. En el corpus analizado, se han usado paremias en el $13 \%$ de los casos y enunciados no fraseológicos en el $87 \%$. Además, lo habitual es que la información o el saber que se utiliza sea de acceso generalizado (65\%), aunque no faltan ejemplos de acceso restringido por uso en área local o ámbito contextual (35\%), y que no se mencione la fuente de información (así es en el 71\% de los casos), si bien ocasionalmente se ofrece con construcciones con gente o la gente (6\%) y variantes (la gente del norte, la mayoría de la gente, mucha gente...) o como alguien, cualquier medio, en muchos sitios, la mayoría de las personas, la televisión, los ancianos, todo el mundo, etc. (en nuestro corpus no se repiten, es decir, aparecen 1 vez cada fuente).

\subsection{Evidencialidad de acervo común: patrones sociopragmáticos en el habla de Madrid}

El objetivo principal de la investigación de la que aquí damos cuenta es conocer si existen patrones sociopragmáticos en la utilización de evidencialidad a través de folclore o acervo común, que nos permitan considerarla una estrategia variable y saber cómo se comportan sociolectos y geolectos al emplearla en su interacción comunicativa natural. Sin duda, los resultados obtenidos en los análisis realizados nos permiten afirmar que nos encontramos ante un fenómeno sociopragmático, y geolectal, que, como ocurre con otras estrategias pragmático-discursivas, es variable y más propia de determinados grupos sociales.

Los datos de 36 horas de grabación (30 minutos con control temporal y temático de 72 entrevistas semidirigidas) informan de que los hombres madrileños hacen mucho más uso de este tipo de evidencialidad que las mujeres (62 casos frente a 38), que los adultos lo emplean considerablemente más que los mayores y que los jóvenes (43 casos, frente a 29 
y a 28, respectivamente), y que los sujetos con estudios medios lo utilizan más que los que tienen estudios primarios y estos, a su vez, más que los que los tienen superiores (43 casos, 32 casos y 25 casos, respectivamente) 4 .

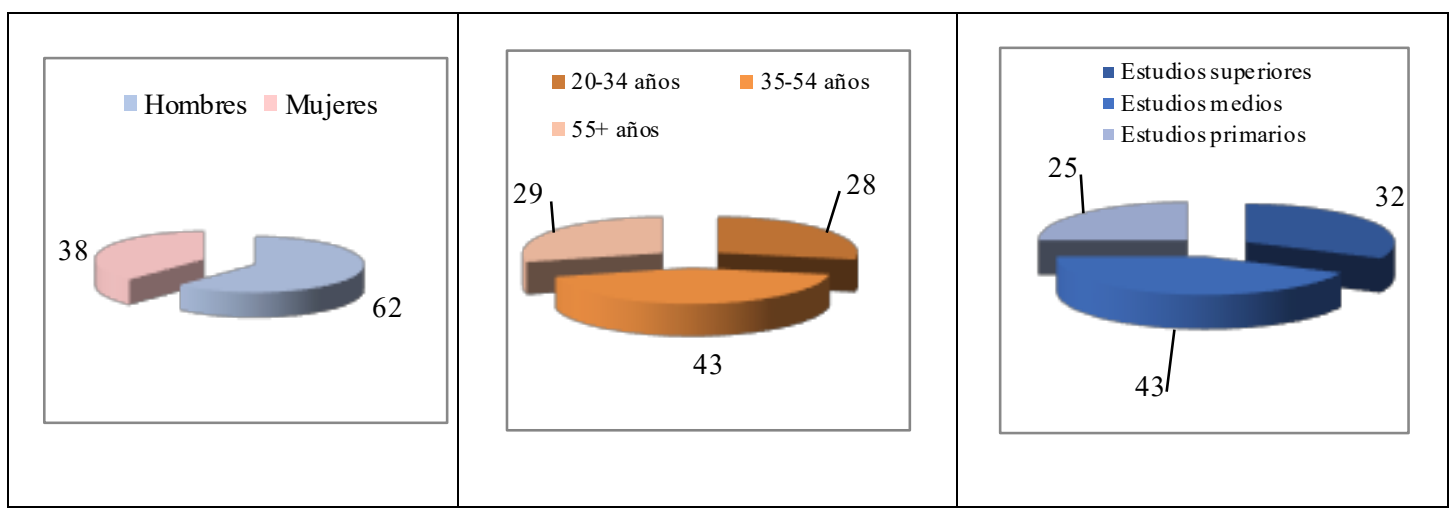

Gráfico 3. Evidencialidad de acervo común: sexo, edad y nivel de instrucción ${ }^{5}$

Ahora bien, para dar cuenta de la estrategia evidencial de los madrileños, hemos de atender al funcionamiento del procedimiento pragmático, así como a su forma de realización, y a grupos de usuarios, mediante cruces de variables e interpretaciones de resultados, pues el comportamiento de hombres y mujeres de diferentes edades y niveles de instrucción no es el mismo, tal y como puede comprobarse en la tabla 1.

\begin{tabular}{|l|l|l|l|l|}
\hline \multirow{2}{*}{ Nivel de instrucción } & \multirow{2}{*}{ Sexo } & \multicolumn{2}{|l|}{ Edad } \\
\cline { 3 - 6 } & & $20-34$ años & $35-55$ años & $55+$ años \\
\hline Estudios primarios & Mujer & 3 & 5 & 3 \\
\hline & Hombre & 8 & 10 & 3 \\
\hline Estudios secundarios & Mujer & 2 & 7 & 6 \\
\hline
\end{tabular}

\footnotetext{
${ }^{4}$ Si tomamos los datos de todo el corpus analizado y los ajustamos según las palabras totales y proporciones en relación a las medias, comprobamos que el patrón sociolectal no varía atendiendo al sexo de los informantes, pero sí, ligeramente, a la edad y al nivel de instrucción: los hombres habrían usado evidencialidad en una proporción del 59,2\% y las mujeres del 40,8\%; los adultos en una proporción del 38,1\%, seguidos de los jóvenes, con 32,1\% y de los mayores, con el 29,8\%, y los sujetos con instrucción primaria en la proporción del 39\%, los de estudios medios, de 35\% y los sujetos con estudios superiores, de $26 \%$.

Por otro lado, si tomamos los datos del corpus completo analizado y los normalizamos con tiempos totales y proporciones en relación con las medias temporales, el patrón sociolectal es, de nuevo, el siguiente: los hombres producen el $60 \%$ de los casos y las mujeres, el 40\%; los adultos son los que hacen un mayor uso de evidencialidad (en una proporción del 39\%), seguidos de los jóvenes (32\%) y de los mayores (29\%); los sujetos con nivel de instrucción primaria producen el $39 \%$ de los casos, seguidos de los de instrucción secundaria (36\%) y de los de instrucción superior (25\%).

Estos resultados se pueden explicar al atender al cruce de variables sociales, pues, en realidad, son grupos específicos (sociolectos en los que se combina sexo, edad y nivel de instrucción) los que con más frecuencia hacen uso de la estrategia que nos ocupa.

${ }^{5}$ Los datos estadísticos correspondientes a la variable sexo son los siguientes: la media es ,62, la desviación típica es de 48; la prueba de $\mathrm{ji}^{2}$ da un valor de sig. asintót. ,016, lo que no nos permite considerar los resultados significativos estadísticamente. Para la variable edad, los datos estadísticos son los siguientes: la media es 2,01, la desviación típica es de ,75; la prueba de $\mathrm{ji}^{2}$ da un valor de sig. asintót. ,121, lo que no permite considerar los resultados significativos estadísticamente. Por último, para la variable nivel de instrucción, los datos estadísticos son los que siguen: la media es 1,93, la desviación típica es de ,75; la prueba de ji² da un valor de sig. asintót. ,085, lo que, de nuevo, no nos permite considerar los resultados significativos estadísticamente. Estos resultados son esperables por el bajo número de casos de evidencialidad de acervo común documentados en el corpus.
} 


\begin{tabular}{|l|l|l|l|l|}
\hline & Hombre & 8 & 9 & 11 \\
\hline Estudios superiores & Mujer & 4 & 6 & 2 \\
\hline & Hombre & 3 & 6 & 4 \\
\hline
\end{tabular}

Tabla 1. Evidencialidad de acervo común: sexo, edad y nivel de instrucción

Son los hombres mayores y adultos, con estudios medios y primarios, los que más uso hacen del tipo de evidencialidad que aquí tratamos. En el caso de las mujeres, sin embargo, son las adultas y las jóvenes, con estudios superiores y medios, las que más la utilizan. El gráfico que ofrecemos a continuación permite apreciar más claramente las diferencias marcadas a las que aludimos.

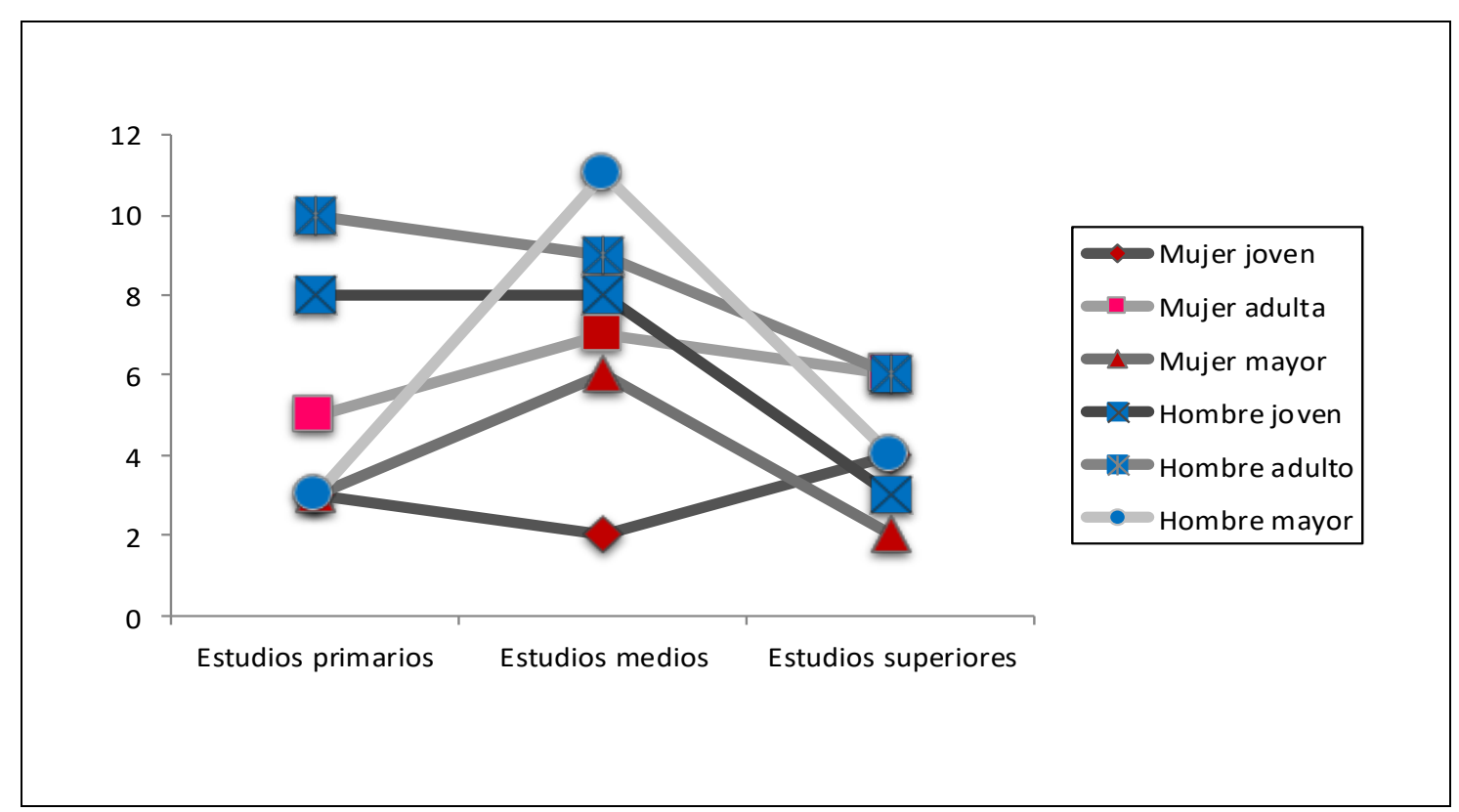

Gráfico 4. Empleo de evidencilidad de acervo común: sexo, edad y nivel de instrucción

Los datos que acabamos de presentar permiten explicar el fenómeno a partir de condicionamientos socioculturales o a partir de una especialización lingüística y funcional que refleja el uso de estrategias interactivas diferentes según factores sociales, especialmente si lo relacionamos con la atenuación, función pragmática para la que se emplea en mayor proporción la evidencialidad a través de folclore o sabiduría popular compartida6, pues indican, en nuestra opinión, que diferentes grupos sociales tienen distintas estrategias para aportar información en interacción, sobre todo, cuando se trata de opinión o información con cierto grado de subjetividad, ya que se implican al hacerlo imágenes, bien la del propio hablante (lo más habitual) o la del interlocutor u otras personas

\footnotetext{
${ }^{6}$ Se aprecia claramente en los resultados que se han obtenido en la investigación sobre atenuación que se viene realizando, desde hace una década, de manera coordinada, en el marco del proyecto PRESEEA, en la que se ha documentado que distintos grupos sociales (hombres, mujeres, jóvenes, adultos, mayores, personas con educación baja, media o alta) utilizan determinados recursos de atenuación más frecuentemente que otros (Albelda, 2012, 2013 y 2018; Albelda y Cestero, 2020; Albelda y otros, 2020; Cestero, 2015 y 2017; Cestero y Albelda, 2012 y 2020; Samper, 2013 y 2017).
} 
que no intervienen en la actividad comunicativa. Como se ha mencionado previamente, la evidencialidad a través de folclore o creencia generalizada es una forma de objetivar la presentación de información, que, así, se atenúa, mediante lo que se considera un proceso de desfocalización o impersonalización, pues se oculta la opinión o consideración personal, la información que se aporta, en sabiduría popular o acervo común -compartida por una amplia mayoría de sujetos o por sujetos de una misma cultura. Es por ello que los resultados de la investigación muestran una correspondencia destacada con los obtenidos en los estudios sobre el empleo de recursos de atenuación en el habla de Madrid (Cestero, 2015, 2017 y 2020), pues, llamativamente, los hombres emplean en mucha mayor proporción recursos de impersonalización para atenuar que las mujeres, quienes prefieren otros tipos de procedimientos más directos y solo ocasionalmente utilizan la desfocalización, y lo mismo ocurre con las personas de diferentes grupos etarios (los adultos emplean en mucha mayor proporción que los mayores y que los jóvenes, y en este orden de frecuencia de uso, la atenuación mediante impersonalización); el nivel de instrucción de los hablantes, no obstante, muestra un patrón sociopragmático distinto si tomamos los datos en su conjunto (pues son los madrileños de instrucción alta los que más atenúan, y lo suelen hacer a través, precisamente, de impersonalizaciones, seguidos por los que tienen estudios secundarios y bajos, en este orden, que hacen uso de la desfocalización para atenuar en muchísima menor proporción), pero que puede relacionarse con las cifras más altas de empleo de evidencialidad que hemos encontrado en las interacciones con mujeres jóvenes y adultas de instrucción superior, por un lado, y con la casi igualdad en el número de casos documentados de empleo de evidencialidad para atenuar en el habla de los sujetos de los tres grupos establecidos por nivel de instrucción (26 en las interacciones con sujeto de nivel de instrucción media y 22 en las que interviene un sujeto con nivel alto y en las que interviene un sujeto con nivel bajo).

Por otro lado, aunque en mucha menor proporción, también es posible hacer uso de la evidencialidad de saber compartido para reforzar la información que se ofrece. Así es en el $28 \%$ de los casos que se han documentado en el corpus analizado, que tienen una distribución muy distinta atendiendo a los grupos sociales con los que trabajamos. Hombres y mujeres producen prácticamente el mismo número de casos (15 y 13, respectivamente); si bien, dado que las mujeres presentan una frecuencia menor de uso de evidencialidad, su utilización como refuerzo argumentativo es, proporcionalmente, mayor que en el caso de los hombres (las mujeres refuerzan con la evidencialidad en el $34,2 \%$ de su uso, mientras que los hombres lo hacen en el $24,2 \%$ ), lo que redunda en la estrategia desfocalizadora más propia de la interacción comunicativa de los madrileños que de las madrileñas. Los grupos etarios presentan una caracterización aún más marcada si la relacionamos con el empleo de la evidencialidad de sabiduría popular para reforzar, pues así la utilizan en una proporción del 17,8\% los jóvenes, del 27,9\% los adultos y del $37,9 \%$ los mayores, apareciendo estos últimos como los que menos usan la estrategia como atenuación y más como refuerzo en el corpus. Finalmente, los sujetos con instrucción primaria evidencian para reforzar en una proporción del 28,1\%, los que tienen instrucción secundaria lo hacen en el $37,2 \%$ y los universitarios, en el $12 \%$, dato que relaciona directamente el mayor uso de evidencialidad de los sujetos de instrucción superior con su empleo desfocalizador atenuador. 
Si atendemos a los resultados sobre el uso funcional de la evidencialidad de acervo común en correlación con las imágenes implicadas en el acto de habla en el que aparece, también obtenemos datos interesantes, que llevan, de manera clara, al fenómeno de atenuación en la interacción comunicativa de los hablantes de la urbe irradiadora de norma. En el caso de las mujeres, la evidencialidad protege mayoritariamente la imagen de otros (así es en el $42,1 \%$ de los casos, frente al $23,7 \%$ en el que protege la imagen propia, al 2,6\% en el que protege la del interlocutor y al 31,6\% en el que no se protege ninguna imagen), mientras que en el caso de los hombres protege la imagen propia (así es en el 43,5\% de los casos, frente al $27,4 \%$ en el que se protege la imagen de otros, al 3,2\% en el que se protege la del interlocutor y al $25,8 \%$ en el que no se protege ninguna imagen). Con relación a los grupos etarios, los jóvenes suelen usar la evidencialidad para proteger su imagen (así es en el $46,4 \%$ de los casos, frente al 32,1\% en el que protegen la imagen de otros, al 3,6\% en el que protegen la del interlocutor y al $17,9 \%$ en el que no protegen imágenes), los adultos para proteger, en cercana proporción, su imagen y la de otros (así es en el 34,9\% y el $30,2 \%$, respectivamente, frente al $4,7 \%$ en el que protegen la imagen del interlocutor y al $30,2 \%$ en el que no protegen ninguna imagen) y los mayores para proteger la imagen de otros (así es en el 37,9\% de los casos, frente al 27,6\% en el que protegen su propia imagen y al $24,5 \%$ en el que no hay imágenes implicadas que proteger). Finalmente, los sujetos con estudios superiores protegen más, mediante evidencialidad de acervo común, la imagen de otros (así es en el $48 \%$ de los casos, frente al $36 \%$ en el que protegen su imagen, al $4 \%$ en el que protegen la imagen del interlocutor y al $12 \%$ en el que no se necesita proteger ninguna imagen), los sujetos de instrucción media protegen casi en la misma proporción la imagen propia y la de otros (así es en el 30,2\% y el 27,9\% de los casos, respectivamente, frente al 3,8\% en los que protegen la imagen del interlocutor y al $35,6 \%$ en los que no protegen ninguna imagen) y los que tienen estudios primarios suelen proteger su propia imagen (así es en el 43,8\% de los casos, frente al 28,1\% en los que protegen la imagen de otros y al $28,1 \%$, también, en el que no hay necesidad de proteger imágenes).

Estos resultados últimos permiten constatar que las mujeres enfocan su actividad comunicativa más hacia los otros, esto es, son más sensibles hacia la figura de los demás en interacción, como ya se documentó en los estudios sobre el uso y funcionamiento de la atenuación en el habla de Madrid (Cestero, 2015, 2017, 2020). Ahora bien, la evidencialidad a través de folclore o acervo común no se puede equiparar, en su uso sociopragmático, a la producción de atenuación, pues son los mayores y los que tienen estudios superiores quienes utilizan más el recurso para proteger la imagen de otros, es decir, mostrándose más sensibles con ello hacia otras personas implicadas por el contenido del discurso que hacia sí mismos7; sin embargo, estos datos pueden relacionarse con el escaso empleo del tipo de evidencialidad en el discurso oral de los madrileños, que lleva a formular la predicción de su desaparición en un devenir habitual: perdura más, en el enfoque hacia los otros, en sociolectos más apegados a los usos tradicionales.

\footnotetext{
${ }^{7}$ En el uso general de la atenuación en el habla de Madrid, los resultados mostraban un comportamiento diferente, pues eran los jóvenes y las personas de instrucción media los que presentaban una mayor proporción de usos para salvaguardar la imagen del interlocutor o de otras personas.
} 
Nos lleva a la consideración de posible cambio hacia la desaparición, además, el hecho de que, en el amplio corpus oral analizado, el empleo de enunciados fraseológicos es ocasional (aparecen solo 13 -el 13\%- en las 36 horas analizadas con control temporal y temático, y 27 -el 17,4\%- en el corpus completo de 63 horas y media) y la información se origina mayoritariamente en creencias compartidas que se expresan mediante construcciones no fijadas en la lengua. Si atendemos a la incidencia de los factores sociales en el mayor o menor empleo de paremias, que son la forma prototípica de evidencialidad de folclore y, por tanto, la tradicional, los datos que ofrecen los análisis realizados resultan de gran interés: las mujeres, en proporción, hacen más uso de las unidades fraseológicas que los hombres (constituyen el 13,2\% del total de casos en las interacciones de las mujeres frente al 12,9\% del empleo que hacen los hombres), los jóvenes y los mayores mucho más que los adultos (25\%, $17 \%$ y 2,3\%) y los sujetos con estudios primarios, más que los que tienen nivel de instrucción media y superior $(21,9 \%, 11,6 \%$ y 4\%, respectivamente). Como se ha explicado previamente, en el caso del corpus de Madrid, la mitad de las encuestas son de personas del distrito de Salamanca, considerado como de clases media y media-alta y la otra mitad del distrito de Vallecas, considerado como de clases media-baja y baja, y este dato que da cuenta de la clase sociocultural es relevante para interpretar los resultados sobre el empleo de unidades fraseológicas en evidencialidad de folclore, pues se han documentado más paremias en las grabaciones de informantes del barrio de Salamanca (13,3\% frente a 12,5\%), más apegados a las formas de prestigio tradicional, especialmente en el habla de sujetos con estudios primarios (6 casos frente a 1), jóvenes y mayores.

\subsection{Influencia del registro en la frecuencia de uso de evidencialidad de acervo común}

La última de las variables tratadas ha sido la de registro de habla. Como se explicó en el apartado de metodología, al igual que en otros estudios sobre el corpus PRESEEA, se ha intentado conocer la posible incidencia del registro, en el empleo, ahora, de evidencialidad de acervo común, considerando que, a medida que se avanza en la interacción semidirigida, se tiende a la informalidad, hecho que está en la base de la configuración misma de las entrevistas. Para ello, se establecen intervalos de 10 minutos; el primero se tiene como de registro más formal, el segundo más neutro o medio y el tercero más informal. Nuestros resultados no muestran diferencia destacada en la producción de evidencialidad de acervo común en los distintos intervalos de tiempo (el 39\% de los casos se da en el primer intervalo, el 29\% en el segundo y el 32\% en el tercero); ahora bien, la mayor frecuencia de uso en el primer intervalo, y en el tercero, nos lleva a relacionar el empleo de la estrategia de presentación del origen de información en saber popular compartido, de nuevo, con recursos más apegados a la tradición. 


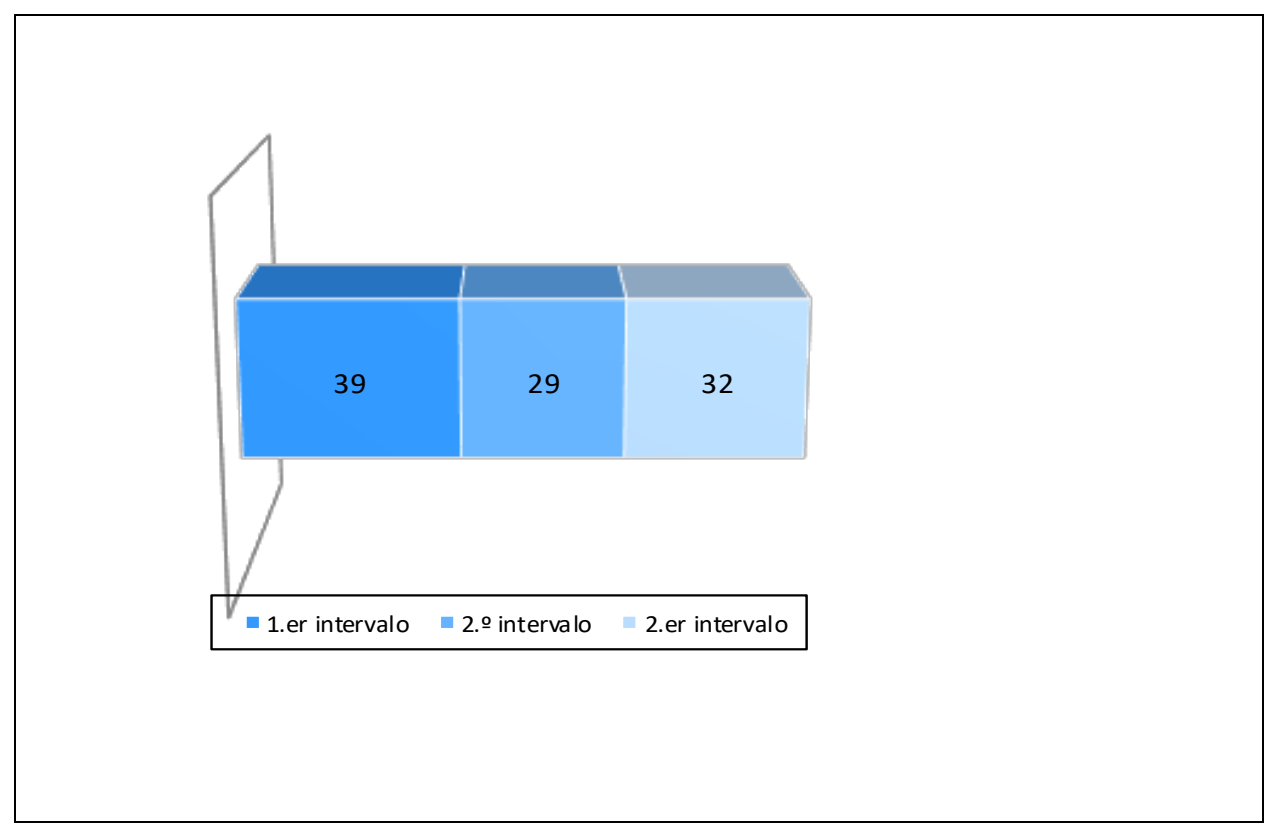

Gráfico 5. Evidencialidad a través de acervo común en el progreso de la interacción

La interpretación sugerida se apoya, además, en el hecho de que el empleo de enunciados fraseológicos se hace mayoritariamente en el primer y segundo tramo (5 casos en el primero, 4, en el segundo, y 4, en el tercero), lo que refleja la asociación entre registros formales y usos tradicionales.

\section{CONCLUSIONES}

En las páginas que preceden hemos presentado los resultados de la primera investigación llevada a cabo para conocer el rendimiento funcional actual de evidencialidad a través de folclore o acervo común en el habla de Madrid, capital irradiadora de norma, desde un acercamiento interdisciplinar. Si bien se considera que los datos generales obtenidos pueden ser explicados por el tipo de actividad interactiva con la que hemos trabajado, 72 entrevistas semidirigidas del corpus PRESEEA-Madrid, como en estudios ya realizados y en marcha sobre otros fenómenos y recursos pragmáticos, llegamos a hallazgos que revelan la existencia de un comportamiento algo diferente por parte de hombres y mujeres, de jóvenes, adultos y mayores, y de personas con nivel de instrucción alto, medio o bajo, lo que nos lleva a pensar, una vez más, en patrones sociopragmáticos en el empleo de estrategias comunicativas.

Los análisis cualitativos y cuantitativos efectuados nos han permitido constatar que los madrileños presentan información originada en acervo común o sabiduría popular compartida muy poco frecuentemente y que es excepcional que usen para ello unidades fraseológicas como refranes, dichos o sentencias, fijadas en la lengua, lo que, unido al hecho de que lo emplean más las personas de sociolectos más apegados a la tradición como norma de prestigio y que aparecen con algo más de asiduidad en estilos tendentes a la formalidad, permite aventurar que se camina hacia su pérdida en la interacción 
comunicativa habitual. Ahora bien, cuando nuestros informantes emplean evidencialidad de acervo común o folclore lo hacen, sobre todo, como estrategia de atenuación que opera desfocalizando, aportando con ello objetividad y generalización para no comprometer su propia imagen o la de otros.

La utilización de paremias no requiere de marcas evidenciales, pues la propia unidad fraseológica ya se asocia a sabiduría popular y folclore directamente. El empleo de otros tipos de enunciados no fijados en la lengua sí requiere marcas de evidencialidad para considerar su uso estratégico; con respecto a ello, ha sido revelador comprobar que las marcas de uso mayoritario son construcciones con el verbo decir, seguidas, aunque muy de lejos, de marcadores de modalidad que pueden ser considerados evidenciales, concretamente de claro y construcciones con verdad. Normalmente se producen las marcas al inicio de la estructura sintáctica del acto de habla, de manera integrada, funcionando como introductor y marcador de la información.

Por último, el uso que hacen los madrileños de evidencialidad de acervo común nos lleva a considerarla un fenómeno variable de carácter sociopragmático, pues los resultados de la investigación sobre el corpus PRESEEA-Madrid indican, en nuestra opinión, que diferentes grupos sociales tienen distintas estrategias que caracterizan su forma de interacción comunicativa. En la capital española, los hombres mayores y adultos, con estudios medios y primarios, y las mujeres adultas y jóvenes, con estudios superiores y medios son los que más emplean el tipo de evidencialidad que tratamos, lo que se relaciona, por un lado, con la atenuación sociopragmática y sus recursos habituales en Madrid y, por otro, con apego al prestigio basado en tradición, que, en la era que vivimos, parece ir dando paso a lo nuevo y lo dinámico. La correlación entre uso de evidencialidad de sabiduría popular compartida, atenuación e implicación de imágenes ofrece otro hallazgo de interés: las madrileñas enfocan su actividad comunicativa hacia los otros, al igual que los mayores y los más instruidos de la urbe, pues son las personas que más usan este procedimiento para salvaguardar imágenes distintas de la propia.

Hemos presentado una primera aproximación al establecimiento de patrones sociopragmáticos en el empleo de evidencialidad de folclore o acervo común en la interacción comunicativa de los madrileños, esperamos que resulte de interés y aliente en el avance en el conocimiento de este procedimiento semático-pragmático, realizando análisis en profundidad que relacionen entre sí diferentes variantes de las variables lingüísticas, pragmáticas y sociales tratadas aquí e identificadas ya como relevantes y, por supuesto, también geolectales. Queda, creemos, establecido un marco teóricometodológico y abierto el sendero para la investigación coordinada.

\section{REFERENCIAS BIBLIOGRÁFICAS}

Albelda Marco, Marta (2012): «Estudio sociolingüístico (piloto) de la atenuación en el corpus PRESEEA de Valencia», en Ridruejo, E., T. Solías, N. Mendizábal y S. Alonso, eds., Tradición y Progreso en la Lingüística General, Valladolid, Universidad de Valladolid, 9-28.
Albelda Marco, Marta (2013): «La atenuación: tipos y estrategias», en Gómez Molina J. R., coord., El español de Valencia. Estudio sociolingüístico, Frankfurt am Main, Peter Lang, 315-343. 
Albelda Marco, Marta (2015): «Evidentiality in nonevidential languages: Are there evidentials in Spanish?», Journal of Pragmatics, 85, 135137.

Albelda Marco, Marta (2016): «Estableciendo límites entre la evidencialidad y la atenuación en español», en González Ruiz, R., D. Izquierdo Alegría y Ó. Loureda Lamas, eds., La evidencialidad en español: teoría y descripción, Madrid, Iberoamericana/Frankfurt am Main, Vervuert, 21-36.

Albelda Marco, Marta (2018): «Variación sociolingüística de los mecanismos mitigadores: diferencias de uso en edad y sexo», Cultura, Lenguaje y Representación, 19, 7-29.

Albelda Marco, Marta (2020): «On the mitigating function of the Spanish evidential se ve que", Corpus Pragmatics, 4, 1, 83-106.

Albelda Marco, Marta y Ana M. Cestero Mancera (2020): «Estudio de variación en el uso de atenuación II: Microanálisis de secuencias discursivas, actos de habla y recursos atenuantes», Revista Signos. Estudios de Lingüística, 53, 104, 962-987, DOI: 10.4067/S0718-09342020000300962.

Albelda, Marta, Ana M. Cestero, Silvana Guerrero y Marta Samper (2020): «Variación sociopragmática y geolectal en el uso de atenuación», Lengua y Habla, 24, 1-53, [en línea]:

$<$ http://erevistas.saber.ula.ve/index.php/lengu ayhabla/article/view/16549>. [Consulta: 11/11/2020]

Albelda, Marta, Antonio Briz, Ana M. Cestero, Dorota Kotwica y Cristina Villalba (2014): «Ficha metodológica para el análisis pragmático de la atenuación en corpus discursivos del español. ES.POR.ATENUACIÓN», Oralia, 17, 7-62.

Bermúdez, Fernando (2005): Evidencialidad: La codificación lingüística del punto de vista, Tesis doctoral, Estocolmo, Universidad de Estocolmo [en línea]: https://www.divaportal.org/smash/get/diva2:199511/fulltext01. [Consulta: 11/11/20]

Boye, Kasper y Peter Harder (2009): «Evidentiality: Linguistic categories and grammaticalization", Functions of Language, 16, 1, 9-43.

Briz, Antonio (2016): «Evidencialidad, significados pragmáticos y partículas discursivas en español. Sobre la intensificación tácticamente evidencial», en González Ruiz, R., D. Izquierdo Alegría y Ó. Loureda Lamas, eds., La evidencialidad en español: teoría y descripción, Madrid, Iberoamericana/Frankfurt am Main, Vervuert, 103-127.
Cestero Mancera, Ana M. (2012): «El proyecto para el estudio sociolingüístico del español de España y América (PRESEEA)», Español Actual, 98, 227-234.

Cestero Mancera, Ana M. (2015): «La atenuación lingüística en el habla de Madrid: un fenómeno sociopragmático variable», en Cestero, A. M., I. Molina y F. Paredes, eds., Patrones sociolingüísticos de Madrid, Frankfurt am Main, Peter Lang, 365-412.

Cestero Mancera, Ana M. (2017): «La atenuación en el habla de Madrid: patrones sociopragmáticos", RILCE, Revista de Filología Hispánica, 33, 1, 57-86.

Cestero Mancera, Ana M. (2020): «Uses and resources of mitigation, in contrast», Spanish in Context, $\quad 17, \quad 2, \quad 362-383$, https://doi.org/10.1075/sic.00063.ces.

Cestero Mancera, Ana M. y Marta Albelda Marco (2012): «La atenuación lingüística como fenómeno variable», Oralia, 15, 77-124.

Cestero Mancera, Ana M. y Marta Albelda Marco (2020): «Estudio de variación en el uso de atenuación I: Hacia una descripción de patrones dialectales y sociolectales de la atenuación en español», Revista Signos. Estudios de Lingüística, 53, 104, 935-961, DOI: 10.4067/S0718-09342020000300935.

Cestero Mancera, Ana M. y Dorota Kotwica (2021a): Guía PRESEEA de estudio de la evidencialidad de folclore o acervo común, Documentos PRESEEA de investigación, Guías de Estudios, 15, https://doi.org/10.37536/PRESEEA.2021.guia $\underline{15}$.

Cestero Mancera, Ana M. y Dorota Kotwica (2021b): «Si todos lo dicen, ¿será cierto? La evidencialidad de folclore o acervo común: de la teoría a la investigación sociopragmática», CLAC. Círculo de Lingüística aplicada a la Comunicación, 86, 151170, https://doi.org/10.5209/clac.72846.

Diewald, Gabriele y Elena Smirnova (2010): «Introduction», en Diewald, G. y E. Smirnova, eds., Evidentiality in European languages: The lexical-grammatical distinction, Berlin, de Gruyter Mouton, 1-14.

Estellés Arguedas, María (2020): «The evolution of parliamentary debates in light of the evolution of evidentials: Al parecer and por lo visto in 40 years of parliamentary proceedings from Spain», Corpus Pragmatics, 4, 1, 59-82.

Estellés Arguedas, María y Marta Albelda Marco (2017): «Evidencialidad, atenuación y descortesía en al parecer y por lo visto. Influencias del género discursivo», en Cornillie, 
B. y D. Izquierdo, eds., Gramática, semántica y pragmática de la evidencialidad, Pamplona, Ediciones Universidad de Navarra, 169-202.

Kittilä, Seppo (2019): "General knowledge as an evidential category», Linguistics, 57, 5, 12711304.

Kittilä, Seppo (2020): «Folklore as an evidential category», Folia Lingüística (published online ahead of print 2020), 1-25, https://doi.org/10.1515/folia-2020-2051.

Kotwica, Dorota (2019): «Valores evidenciales de o eso dicen», Pragmalingüística, 27, 8-26, http://dx.doi.org/10.25267/Pragmalinguistica. 2019.i27.04.

Kotwica, Dorota (2020a): «Evidencialidad, conocimientos compartidos y atenuación: el caso de '[0] eso dicen'», Revista Signos. Estudios de Lingüística, 53, 104, 765-789, DOI: 10.4067/S0718-09342020000300765.

Kotwica, Dorota (2020b): «Mitigation and reinforcement in general knowledge expressions», Journal of Pragmatics, 169, 219-230.

Kotwica, Dorota (2021): «Evidencialidad a través de acervo común: patrones sociopragmáticos en el habla de Valencia», Normas, 11 (1).

Lazard, Gilbert (2001): «On the grammaticalization of evidentiality", Journal of Pragmatics, 33, 359-367.
Moreno Fernández, Francisco (1996): «Metodología del 'Proyecto para el estudio sociolingüístico del Español de España y de América' (PRESEEA)», Lingüística, 8, 257-287.

Moreno Fernández, Francisco (2006): «Información básica sobre el "Proyecto para el Estudio Sociolingüístico del Español de España y de América - PRESEEA (1996-2010)», Revista Española de Lingüística, 36, 385-391.

Moreno Fernández, Francisco y Ana M. Cestero Mancera (2020): «El proyecto PRESEEA: desarrollos analíticos», Verba, Anexo 80, 119138 ,

https://dx.doi.org/10.15304/9788418445316.

Samper Hernández, Marta (2013): «La atenuación lingüística en el español de Las Palmas de Gran Canaria», Lingüística Española Actual, 35, 2, 325-348.

Samper Hernández, Marta (2017): «Análisis sociolingüístico de la atenuación en el español de Las Palmas de Gran Canaria”, en Albelda, M. y W. Mihatsch, eds., Atenuación e intensificación en diferentes géneros discursivos, Madrid, Iberoamericana/Frankfurt am Main, Vervuert, 153-168.

Willett, Thomas (1988): «A Cross-Linguistic Survey of the Grammaticalization of Evidentiality», Studies in Language, 12, 51-97. 